\title{
Revestimento bioativo à base de fécula de mandioca (Manihot esculenta) e beterraba acrescido de óleo de copaíba bálsamo (Copaifera officinalis) para conservação de carne bovina in natura
}

\author{
Bioactive coating based on cassava starch (Manihot esculenta) and beet with copaiba balm oil \\ (Copaifera officinalis) for preserving fresh beef \\ Recubrimiento bioactivo a base de almidón de yuca (Manihot esculenta) y remolacha con aceite de \\ bálsamo de copaiba (Copaifera officinalis) para conservar la carne fresca
}

Recebido: 15/01/2021 | Revisado: 20/01/2021 | Aceito: 03/02/2021 | Publicado: 09/02/2021

\author{
Ildrianne Ilana Marins de Sá Souza \\ ORCID: https://orcid.org/0000-0002-4099-8798 \\ Universidade de Pernambuco, Brasil \\ E-mail: ildrianne99@gmail.com \\ Regina Lúcia Félix Aguiar Lima \\ ORCID: https://orcid.org/0000-0003-4618-9147 \\ Universidade de Pernambuco, Brasil \\ E-mail: regina.aguiar@upe.br \\ Claudileide de Sá Silva \\ ORCID: https://orcid.org/0000-0002-3677-3000 \\ Universidade de Pernambuco, Brasil \\ E-mail: claudileide.silva@upe.br
}

\begin{abstract}
Resumo
O mercado agropecuário brasileiro tem crescido e ocupado cada vez mais espaço na economia mundial. O Brasil é o segundo maior produtor e consumidor de carne bovina, atrás apenas dos Estados Unidos. Os fatores intrínsecos da carne contribuem para a proliferação microbiana e rápida deterioração, surgindo a necessidade produzir uma alternativa natural para a conservação de alimentos, sendo acessível e com baixo custo para a população. O trabalho teve por objetivo avaliar o potencial de conservação do gel da Manihot esculenta adicionado óleo essencial de copaíba (Copaifera officinalis) e extrato de beterraba (Beta vulgaris L.) na extensão da vida de prateleira da carne bovina. O potencial antimicrobiano do óleo de copaíba foi determinado com a difusão em disco, determinação das concentrações inibitórias e bactericidas mínimas do óleo por microdiluição, composição química, vida de prateleira através da cor, $\mathrm{pH}$ e microbiota durante o período de armazenamento das amostras controles e tratamento. Dentre os resultados, o pH inicial da amostra controle foi 5,25 $\pm 0,05$ e final 5,93 $\pm 0,03$, a amostra OCB $5,28 \pm 0,01$ ao final $5,37 \pm 0,008$ e a amostra BET entre 5,21 $\pm 0,08$ a 5,39 $\pm 0,05$. Já, a análise microbiológica inicial da amostra controle dos mesófilos aos 20 minutos de 3,06 para 5,27 log UFC/g no $7^{\circ}$ dia, a amostra OCB iniciou 3,26 para 5,14 log UFC/g e a amostra BET, partiu de 3,39 a 4,73 log UFC/g. Os resultados obtidos despertam próximos estudos para exploração de novas dosagens nesta matriz.
\end{abstract}

Palavras-chave: Carne bovina; Vida de prateleira; Óleo bálsamo; Copaifera officinalis; Manihot esculenta.

\begin{abstract}
The Brazilian agricultural market has grown and occupies more and more space in the world economy. Brazil is the second largest producer and consumer of beef, behind only the United States. The intrinsic factors of meat contribute to microbial proliferation and rapid deterioration, and there is a need to produce a natural alternative for food preservation, being accessible and at a low cost to the population. The objective of this work was to evaluate the conservation potential of Manihot esculenta gel added with copaiba essential oil (Copaifera officinalis) and beet extract (Beta vulgaris $L$.) in extending the shelf life of beef. The antimicrobial potential of copaiba oil was determined by disc diffusion, determination of the minimum inhibitory and bactericidal restrictions of the oil by microdilution, chemical composition, shelf life through color, $\mathrm{pH}$ and microbiota during the period of storage of controls and control. Among the results, the initial $\mathrm{pH}$ of the control sample was $5.25 \pm 0.05$ and the final $5.93 \pm 0.03$, the OCB sample $5.28 \pm 0.01$ at the end $5.37 \pm 0.008$ and the BET sample between $5,21 \pm 0.08$ to $5.39 \pm 0.05$. An initial microbiological analysis of the control sample of mesophiles at 20 minutes from 3.06 to $5.27 \log$ UFC / g on the 7th day, the OCB sample started 3.26 to $5.14 \log$ UFC / g and the BET sample, started from 3.39 to $4.73 \log$ UFC / g. The results obtained arouse studies to explore new dosages in this matrix.
\end{abstract}


Keywords: Beef; Shelf life; Balsam oil; Copaifera officinalis; Manihot esculenta.

\section{Resumen}

El mercado agrícola brasileño ha crecido y ocupa cada vez más espacio en la economía mundial. Brasil es el segundo mayor productor y consumidor de carne vacuna, solo detrás de Estados Unidos. Los factores intrínsecos de la carne contribuyen a la proliferación microbiana y al rápido deterioro, y existe la necesidad de producir una alternativa natural para la conservación de alimentos, accesible y de bajo costo para la población. El objetivo de este trabajo fue evaluar el potencial de conservación del gel de Manihot esculenta agregado con aceite esencial de copaiba (Copaifera officinalis) y extracto de remolacha (Beta vulgaris L.) para extender la vida útil de la carne vacuna. El potencial antimicrobiano del aceite de copaiba se determinó mediante difusión en disco, determinación de las restricciones mínimas inhibitorias y bactericidas del aceite por microdilución, composición química, vida útil a través del color, $\mathrm{pH}$ y microbiota durante el período de almacenamiento de controles y control. Entre los resultados, el pH inicial de la muestra de control fue $5.25 \pm 0.05$ y el final $5.93 \pm 0.03$, la muestra OCB $5.28 \pm 0.01$ al final $5.37 \pm 0.008$ y la muestra BET entre $5,21 \pm 0,08$ a 5,39 $\pm 0,05$. Un análisis microbiológico inicial de la muestra de control de mesófilos a los 20 minutos de 3.06 a 5.27 log UFC / g en el séptimo día, la muestra de OCB comenzó 3.26 a $5.14 \log$ UFC / gy la muestra BET, comenzó de 3,39 a 4,73 log UFC / g. Los resultados obtenidos despiertan estudios para explorar nuevas dosificaciones en esta matriz.

Palabras clave: Carne; Duracion; Aceite de bálsamo; Copaifera officinalis; Manihot esculenta.

\section{Introdução}

A atividade pecuária possui grande relevância para economia brasileira. Esse setor vem ganhando destaque no cenário nacional e mundial, devido a constante evolução e expansão no mercado. Dados registrados pela Associação Brasileira das Indústrias Exportadoras de Carnes (ABIEC) demonstram que Produto Interno Bruto (PIB) e o valor monetário arrecadado no ano de 2018, superaram positivamente o ano anterior (ABIEC, 2019).

Desde o ano de 2015, o rebanho bovino brasileiro é considerado o maior no mundo para fins comerciais, além de ser considerado o segundo maior consumidor e exportador da carne bovina, atrás apenas dos Estados Unidos (Carvalho \& Zen, 2017).

Em virtude de suas características intrínsecas que a tornam um produto de alta perecibilidade, é mais suscetível ao surgimento de Doenças Transmitidas por Alimentos (DTA). Desse modo, a carne bovina pode sofrer contaminação microbiológica e acelerar a degradação de glicogênio por via endógena, quando o animal ainda está vivo e de maneira exógena, no período após a morte, denominado de post mortem (Palma, 2017).

No Brasil, em 2018, pelo menos 18.992 pessoas foram expostas as DTA, sendo contabilizados 503 casos de surtos e 731 hospitalizações resultando em 9 óbitos, cujas análises confirmaram a Escherichia coli (E. coli) como agente etiológico em 41 surtos e a Salmonella spp em 13 surtos, sendo estes os patógenos mais preocupantes (Brasil, 2019). Segundo a legislação vigente, os níveis toleráveis de microrganismos são 25g de Salmonella spp em carnes bovinas "in natura", resfriadas ou congeladas (ANVISA, 2001). Embora não haja a quantificação exata dos gastos públicos com essas doenças, há a necessidade de políticas públicas efetivas, que visem garantir o acesso a alimentos seguros, saudáveis e próprios para o consumo humano (Gomes, 2015).

Em relação a deterioração, sabe-se que a partir do armazenamento e processamento inadequados, a carne bovina refrigerada torna-se mais propensa a deterioração microbiana de psicotróficos como Pseudomonas (P. aeruginosa), Acinectobacter, Moxarella e Aeromonas, pois, possuem maior afinidade com a temperatura de resfriamento de $0^{\circ}$ a $7{ }^{\circ} \mathrm{C}$ (Soares, Silva \& Góis, 2017).

Neste sentido, no processo de conservação, a embalagem é indispensável tanto para garantia da segurança microbiológica, como para a qualidade nutricional e sensorial (cor, sabor, aroma) da carne bovina (Moraes \& Junior, 2016). Com esse propósito, é crescente o emprego de embalagens ativas, sendo biodegradáveis, capazes de absorver umidade, reduzir o desperdício, aumentar a qualidade do produto e sua vida de prateleira (Nollêto, 2018). 
Para aprimorar as embalagens biodegradáveis, há o acréscimo de outras substâncias. O extrato de beterraba roxa (Beta vulgaris $L$.), por sua vez, é um produto natural e possui alta concentração de betalaína em sua composição (Gonçalves, et al., 2015; Guerreiro-Rubio, et al., 2020). Esse composto pigmentoso é responsável por conferir coloração e sabor marcantes e exerce atividades antimicrobiana, antioxidante, antitumoral, anti-inflamatória (Sarker, et al., 2018; Guerreiro-Rubio, et al., 2020).

No mesmo contexto, os óleos essenciais são capazes de promover atividade antimicrobiana, associados ou não a outras substâncias. Dentre eles estão, o óleo de copaíba bálsamo (Copaifera officinalis), amplamente utilizado no Brasil em virtude de suas funções: anti-inflamatória, antisséptica, cicatrizante em feridas e lesões (Sousa, 2018).

Desse modo, o presente trabalho visou contribuir com alternativas naturais para a conservação de alimentos e que possuam baixo custo e fácil acesso para a população. Ao utilizar o óleo de copaíba bálsamo (Copaifera officinalis) com o extrato da beterraba (Beta vulgaris L.) e o gel da fécula de mandioca (Manihot esculenta) no combate a deterioração das carnes, buscou estender sua vida de prateleira e evitar alterações indesejáveis no produto.

\section{Metodologia}

\section{Desenho do estudo}

Trata-se de um estudo experimental, cujos tratamento se deram através da utilização de um gel produzido com fécula de mandioca (Manihot esculenta), extrato de beterraba (Beta vulgaris L.) e adicionado de óleo de copaíba bálsamo (Copaifera officinalis). Desse modo, as amostras foram definidas como: amostra controle (sem nenhum tipo de tratamento), OCB, ou seja, amostras foram tratadas com gel da fécula de mandioca (Manihot esculenta) contendo 15\% de extrato de beterraba e óleo bálsamo de copaíba (Copaifera officinalis) a $10 \mu / \mathrm{mL}$, e amostras BET, as quais foram tratadas apenas com o gel de fécula de mandioca contendo $15 \%$ de extrato de beterraba.

\section{Obtenção e caracterização química do óleo de copaíba bálsamo (Copaifera officinalis)}

O óleo de copaíba bálsamo (Copaifera officinalis) utilizado foi obtido através da Ferquima Indústria e Comércio LTDA. Sua composição química foi realizada por cromatografia gasosa, utilizando cromatógrafo de gás AGILENT 7820A (GC) com uma coluna capilar HP-5 $(30 \mathrm{~m} \times 0,32 \mathrm{~mm} \times 0,5 \mu \mathrm{m})$. O detector FID foi utilizado à temperatura de $250{ }^{\circ} \mathrm{C}$ e com energia de ionização de $70 \mathrm{eV}$, no modo de impacto de elétrons.

\section{Teste de difusão em meio sólido}

O método difusão em disco foi utilizado na verificação do efeito inibitório dos óleos contra microrganismos como Listeria monocytogenes, P. aeruginosa, Staphylococcus aureus e Escherichia coli. Dessa maneira, o método foi utilizado para detectar a sensibilidade dessas cepas bacterianas, as quais foram utilizadas contendo aproximadamente $1,5 \times 10^{8} \mathrm{UFC} / \mathrm{ml}$, e inoculadas em meio ágar Mueller Hinton (Kasvi, Itália).

Com a solidificação do meio, houve o acréscimo de discos de papel filtro estéril (Oxoid) de $6 \mathrm{~mm}$ de diâmetro embebidos com $10 \mu \mathrm{L}$ do óleo, outro disco em água deionizada estéril e outro com antibiótico Meropenem (10 mg, Oxoid), estes dois últimos como controles negativo e positivo, respectivamente. Em seguida, as placas foram incubadas a $37{ }^{\circ} \mathrm{C}$ por 24 horas.

Após o período de incubação, houve a aferição das medidas do diâmetro das zonas de inibição e o diâmetro dos discos, ambos em milímetros. Foi utilizada a classificação de Ponce, et al., (2003) que indica a sensibilidade das cepas bacterianas ao óleo, sendo considerada não sensível, quando diâmetro total for menor que $8 \mathrm{~mm}$, sensível para diâmetro total 
entre 9 a $14 \mathrm{~mm}$, muito sensível para diâmetro total de 15 a $19 \mathrm{~mm}$ e extremamente sensível, quando o diâmetro total superou $20 \mathrm{~mm}$. Os ensaios foram realizados em duplicata.

\section{Determinação da concentração inibitória mínima (cim) e concentração bactericida mínima (cbm)}

As cepas padrão foram cedidas pelo Laboratório experimental de análise de alimentos (LEAAL) do Departamento de Nutrição, da Universidade Federal de Pernambuco (UFPE).

Os inóculos das cepas bacterianas foram preparados a partir da suspensão em solução salina estéril $(\mathrm{NaCl})$ a $0,85 \%$, logo após, as bactérias foram descongeladas e crescidas durante a noite em caldo BHI à $37^{\circ} \mathrm{C}$ (Carvalho, et al., 2015, Silva al., 2019). A turbidimetria foi ajustada para 0,5 da escala McFarland e padronizada sob espectrofotômetro (KAZUAKI, IL-592LC). Para determinar a CBM e CIM, a suspensão bacteriana e o óleo foram submetidos a microdiluição em microplacas de 96 poços contendo caldo Mueller Hinton (Kasvi, Itália) e incubadas a $37 \pm 1{ }^{\circ} \mathrm{C}$ por 24 horas.

Após esse período de incubação, houve o acréscimo de uma alíquota de $30 \mu \mathrm{L}$ de resazurina $(0,01 \%, \mathrm{~m} / \mathrm{v})$ (INLAB, Brasil) preparada em solução aquosa e adicionada ao poço como descrito por Carvalho, et al., 2015. Por volta de 20 minutos de incubação percebendo-se mudança visual da coloração, onde, incialmente era azul modificando para rosa ou roxo, indicando crescimento bacteriano.

Efeito da adição do óleo de copaíba bálsamo (Copaifera officinalis) no tempo de vida de prateleira da carne bovina: PH, cor, análise microbiológica

\section{Produção do gel da fécula de mandioca (Manihot esculenta)}

A fécula de mandioca foi o amido escolhido para o presente estudo. Adquirida em um supermercado no município de Petrolina - PE. Para a elaboração do gel foi utilizada uma panela antiaderente, adicionada a fécula de mandioca acrescida da água destilada em aquecimento constante e em seguida adicionado o óleo na proporção de $10 \mu \mathrm{L} / \mathrm{g}$ para o óleo bálsamo de copaíba (Copaifera officinalis).

\section{Preparo das amostras de carne}

A carne bovina (Longissimus dorsi) foi adquirida em mercado local, de marca conhecida e consolidada no mercado consumidor, visando a melhor condição higiênico-sanitária e microbiológica do produto. Posteriormente foram fracionadas em porções de $10 \mathrm{~g}$ e mergulhadas no gel, com exceção da amostra controle. Após secagem por 10 minutos em capela de fluxo laminar, foram colocados em saco estéril para análise de alimentos (Nasco), em duplicatas, e em seguida, armazenadas sob refrigeração $\left(4 \pm 1^{\circ} \mathrm{C}\right)$ por 20 minutos, 4 e 7 dias.

\section{Análise de pH}

A medição do $\mathrm{pH}$ foi realizada no intervalo de 20 minutos, 4 e 7 dias, em que as amostras controle e as tratadas, foram mensuradas por meio da potenciometria de acordo com a metodologia descrita pela AOAC (AOAC, 1995), utilizando um medidor de pH digital (Tecnopon, MPA 210).

\section{Análise de cor}

Um fator a ser observado como garantia do tempo de vida de prateleira adequado é a coloração da carne, com isso, a cor da carne foi avaliada durante o armazenamento aos 20 minutos, 4 e 7 dias, usando o colorímetro digital e portátil (Landtek CM-2005, China) equipado com uma luz D65, a uma geometria do ângulo de visão de $0^{\circ}$ de acordo com as coordenadas de refletância (L*, a*, b*; CIE 1976). 


\section{Análise microbiológica}

As análises microbiológicas foram realizadas no período de 20 minutos, 4 e 7 dias, sendo contadas as bactérias $P$. aeruginosa em meio ágar cetrimide (Merck, Alemanha, $25^{\circ} \mathrm{C}$ por $48 \mathrm{~h}$ ), os coliformes totais e $E$. coli obtidas a partir da análise das placas 3M Petrifilm TM (3M, Estados Unidos) e as contagens mesófilas aeróbias totais realizadas em meio Plate Count Agar (PCA; Merck, Alemanha; $35^{\circ} \mathrm{C}$ por $48 \mathrm{~h}$ ), de acordo com os métodos oficiais de análise OMA \#998.08 para aves domésticas, carnes e frutos do mar. Todas análises foram realizadas em duplicata.

\section{Análise estatística}

Para melhor estruturação, um banco de dados foi elaborado por meio do software EXCEL (versão office home, 2018). As análises estatísticas foram realizadas por meio do programa Prism versão 5.0 (GraphPad, USA) através da estatística descritiva (média e desvio padrão, onde o nível de significância $\mathrm{p}<0,05$ foi adotado para todos os dados experimentais. $\mathrm{E}$ utilizado o two-way ANOVA com pós-teste de Bonferroni para analisar o efeito do tratamento de inibição do óleo contra os microrganismos analisados sobre $\mathrm{pH}$, coloração e o tempo de vida de prateleira.

\section{Resultados e Discussão}

\section{Composição química do óleo de copaíba bálsamo (Copaifera officinalis)}

A análise da composição química do óleo de copaíba bálsamo (Copaifera officinalis), evidenciou maiores concentrações dos componentes $\beta$-cariofileno (70\%) e humuleno (10\%) (Tabela 1).

O $\beta$-cariofileno é um dos terpenóides presentes em abundância no óleo de copaíba bálsamo (Copaifera officinalis), os quais são divididos em: cariofileno, humuleno e copaeno, que são compostos voláteis, diterpenos que possuem aspecto resinoso como os ácidos caurenóico, copálico e polialítico, os quais são compostos não voláteis (Arruda, et al., 2019).

Tabela 1 - Composição química (\%) do óleo de copaíba bálsamo (Copaifera officinalis).

\begin{tabular}{lll}
\hline Copaifera officinalis & Composição (\%) & Outros estudos* \\
\hline$\beta$-cariofileno & 70 & $40-57$ \\
Humuleno & 10 & $4,27-5,4$ \\
$\alpha$-copaeno & 7 & $0,5-5,65$ \\
Gemacreno d & 2 & 15,86 \\
$\Delta$-cadileno & 2 & $1,57-3,17$ \\
$\gamma$-cadileno & 1 & 1,57 \\
$\beta$-clemento & 1 & 1,15 \\
\hline
\end{tabular}

*Dias et al. (2012), Guimarães-Santos et al. (2012), Sousa et al. (2020). Fonte: Ferquima (2020).

Apesar da diferença entre as espécies, estudos já comprovam que o $\beta$-cariofileno é o composto presente em maior proporção no óleo de copaíba bálsamo (Copaifera officinalis), sendo considerado um sesquiterpeno natural e possui um caráter antimicrobiano, cicatrizante e anti-inflamatório, de extrema relevância para a saúde. Enquanto o óleo do estudo apresentou aproximadamente 70\% dessa substância, em outros estudos (Dias, et al., 2012; Guimarães-Santos, et al., 2012; Ferro, et al., 2018; Arruda, et al., 2019; Francomano, et al., 2019; Sousa, et al, 2020) evidenciaram a presença de apenas $40 \%$ a $57 \%$ de $\beta$ cariofileno. As diferentes concentrações relatadas, podem ser atribuídas a época de colheita e sua fonte geográfica (Boskovic, et al., 2015), a época da extração do óleo, se no período ou após a floração, sendo no primeiro caso a atividade a antimicrobiana mais forte (Burt, 2004). 


\section{Teste de difusão em meio sólido e determinação da concentração inibitória mínima (CIM) e concentração bactericida} mínima $(\boldsymbol{C B M})$

Ao observar a sensibilidade das cepas bacterianas às substâncias analisadas, por meio do teste de difusão em meio sólido, pode-se notar que as $P$. aeruginosa não são sensíveis ao antibiótico Meropenem, pois a média do diâmetro foi de 8 mm $(\mathrm{DP} \pm 0)$ e em relação ao óleo de copaíba bálsamo (Copaifera officinalis), com média de 7,5 mm (DP \pm 1,5, não sensível).

De acordo com resultados relatados por Kamarezi, et al., (2012), a P. aeruginosa também não foi sensível aos óleos essenciais de Curcuma aeruginosa, Curcuma mangga e Zingiber cassumunar, por ser gram-negativa, a sua morfologia é mais resistente à ação de antimicrobianos, tanto aos antibióticos como aos óleos essenciais.

No entanto, a cepa de Staphyloccus aureus foi extremamente sensível ao antibiótico, apresentando 23 mm de diâmetro $(\mathrm{DP} \pm 3)$, e sensível ao óleo, com diâmetro $10 \mathrm{~mm}$ ( $\mathrm{DP} \pm 0$ ). Esse resultado pode confirmar o fato de as bactérias grampositivas serem mais sensíveis a determinados compostos do que as gram-negativas, o que pode ser atribuído a sua estrutura celular mais simples (Kamarezi, et al., 2012; Pombo, et al., 2018).

A cepa de Listeria monocytogenes foi extremamente sensível para ambos compostos, com halo de inibição de 21,5 mm (DP \pm 0,5) de diâmetro para o tratamento com o antibiótico, e de 20,5 mm (DP \pm 0,5) quando tratada com óleo de copaíba bálsamo (Copaifera officinalis). Resultados favoráveis sobre os óleos essenciais também foram observados no estudo de Rasooli, et al. (2006) em relação ao óleo essencial de tomilho (Thymus spp.) contra a cepa de Listeria monocytogenes, cujo diâmetro do halo de inibição variou de 19 a 38 mm, partindo da categoria sensível para extremamente sensível. Silva, et al. (2019) utilizando óleo essencial de tea tree (Melaleuca alternifolia) contra cepas de Listeria monocytogenes, constatou halo de inibição de $30 \pm 8.8 \mathrm{~mm}$, extremamente sensível. Estes resultados são relevantes, pois a listeriose é uma toxinfecção que apesar da baixa prevalência, possui alto risco morte para a população (Shourav, et al., 2020).

Após a realização dos testes de microdiluição, foi constatada uma CIM de $5 \mu \mathrm{L} / \mathrm{ml}$ e CBM de $10 \mu \mathrm{L} / \mathrm{ml}$ em relação ao óleo de copaíba bálsamo (Copaifera officinalis) contra a cepa Listeria monocytogenes, a qual devido a sua gravidade foi tomada como referência.

\section{Valores de pH e cor durante o armazenamento}

$\mathrm{O}$ pH é um parâmetro fundamental para determinar a qualidade e estabilidade da carne, podendo inferir a integridade das proteínas (Alarcon-Rojo, et al., 2019). Neste sentido, o pH da carne própria para o consumo deve ser mantido de 5,8 a 6,4. Durante o armazenamento, esse pH tende a aumentar em torno de 6,5 a 7,5 indicando o estágio inicial de deterioração da carne, em virtude da proliferação microbiana (Franco \& Landgraf, 2008; Soares, et al., 2017; Martins, 2017). No estudo presente estudo, conforme descrito na Tabela 2.

Tabela 2 - Valores de $\mathrm{pH}$ das amostras de carne em armazenamento, durante 20 minutos, 4 e 7 dias sob temperatura de $4 \pm 1{ }^{\circ} \mathrm{C}$.

\begin{tabular}{llll}
\hline Amostra & 20 minutos $^{*}$ & 4 dias* $^{*}$ & 7 dias* $^{*}$ \\
\hline Controle $^{\mathrm{a}}$ & $5,25 \pm 0,05^{\mathrm{d}}$ & $5,55 \pm 0,15$ & $5,93 \pm 0,03$ \\
OCB $^{\mathrm{b}}$ & $5,28 \pm 0,01$ & $5,2 \pm 0$ & $5,37 \pm 0,008$ \\
BET $^{\mathrm{c}}$ & $5,21 \pm 0,08$ & $5,45 \pm 0,05$ & $5,39 \pm 0,05$ \\
\hline
\end{tabular}

${ }^{a}$ Controle (apenas fécula de mandioca)

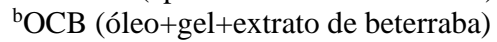

${ }^{\mathrm{c} B E T}$ (somente o extrato)

*Valores expressos em média e desvio-padrão

Fonte: Autores. 
É notável que apesar de manter um pH inicial de 5,2 e final de 5,9 para amostras controle, e de 5,3 para as amostras tratamento, não houve variações significativas ( $p>0,05)$, e assim para este parâmetro as amostras se mantiveram dentro dos valores considerados aceitáveis. $\mathrm{O}$ aumento do $\mathrm{pH}$ da amostra controle permaneceu constante partindo aos 20 minutos do $5,25 \pm 0,05$ para 5,93 $\pm 0,03$ ao $7^{\circ}$ dia. Já, a amostra OCB (óleo, gel e extrato de beterraba) de 5,28 $\pm 0,01$ para 5,37 $\pm 0,008$, indicando uma maturação da carne comum nesse período. E a amostra BET, apesar de haver um pico com leve aumento no $4^{\circ}$ dia, se manteve também constante.

Comparando os resultados do estudo, com os outros semelhantes (Pereira, et al., 2006; Limoni, et al., 2017; Zhang, et al., 2018), pode-se notar que o leve aumento do $\mathrm{pH}$ ou sua estabilidade podem ocorrer devido a redução das reservas de glicogênio ainda presente no músculo.Em relação a coloração, este é um dado que deve ser considerado devido à importância comercial já que o consumidor, ao comprar gêneros alimentícios, é atraído pelo aspecto visual (Kim, et al., 2020; Rodrigues \& Pozza, 2020; Salueña, et al., 2019). Neste sentido, os valores de $a^{*}>0$ indicam que foram positivos e predominaram a coloração vermelha, característica da carne e mais atraente na hora da compra, estes dados podem ser observados na Figura 1.

Figura 1 - Valor de a* durante o armazenamento 20 minutos, 4 e 7 dias de armazenamento, de amostras de carne controle e tratadas com $10 \mu \mathrm{L} / \mathrm{g}$ de óleo copaíba bálsamo (Copaifera officinalis).

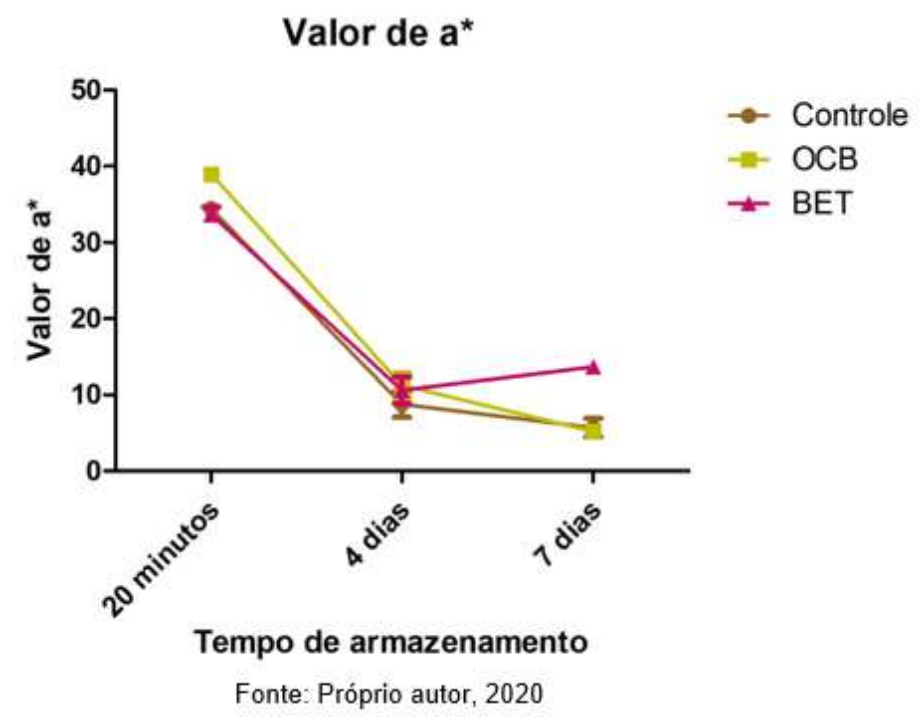

Os valores de $\mathrm{a}^{*}$, apresentados na Figura 1, da amostra controle foram de 34,45 \pm 0,11 aos 20 minutos, partindo para $8,75 \pm 1,68$ ao $4^{\circ}$ dia e ao $7^{\circ}$ dia, $6,9 \pm 4,46$, indicando assim, que através da redução dos valores a*, a coloração da carne pode ter sido estabilizada e mantida devido a presença do gel, que fornece uma barreira contra a penetração de oxigênio somado a temperatura de armazenamento (Cardoso, 2011).

Ao analisar a Figura 1, pode-se perceber que a amostra OCB apresenta aos 20 minutos a* 38,98 \pm 0,65 e uma cor mais brilhante e intensa, que pode estar relacionado a presença do gel, óleo e do extrato beterraba (Beta vulgaris L.). Porém, é observada redução de $\mathrm{a}^{*}$ ao $4^{\circ}$ dia, $11,26 \pm 1,6$ e ao $7^{\circ}$ dia, $5,2 \pm 0,36$.

Os resultados da amostra de BET foram aparentemente melhores nos dois primeiros tempos (20 minutos e 4 dias), mas, não houve diferença significativa ao $7^{\circ}$ dia. Onde, aos 20 minutos, o valor de BET foi 33,7 $\pm 0,96$, já ao $4^{\circ}$ dia, $10,61 \pm$ 1,71 e ao $7^{\circ}$ dia, $13,68 \pm 0,28$.

Assim como no estudo de Salueña, et al. (2019), os valores de a* podem ter sofrido uma redução em detrimento da maturação da carne em consequência da oxidação, tendo sido essa redução significativa ( $p<0,001)$. 
A Figura 2 indica os valores de $b^{*}$ que apresentaram diferença estatística em todos os tempos, quando comparadas as amostras controle $(\mathrm{p}<0,001)$. Assim, como $\mathrm{a}^{*}$, os valores foram positivos e reduzidos conforme o tempo de armazenamento (Al-Hijazeen, et al., 2016). Todavia, b* indica a coloração azul e amarela. A mudança na coloração pode ser resultado da oxidação lipídica (Rimini, et al., 2014; Salueña, et al., 2019), variação na concentração de mioglobina e ainda ser afetada, pelo pigmento de hemoglobina presente nos músculos conforme descrito por Tekce, et al., (2020).

Figura 2. Valor de $b^{*}$ durante o armazenamento 20 minutos, 4 e 7 dias de armazenamento, de amostras de carne controle e tratadas com $10 \mu \mathrm{L} / \mathrm{g}$ de óleo copaíba bálsamo (Copaifera officinalis).

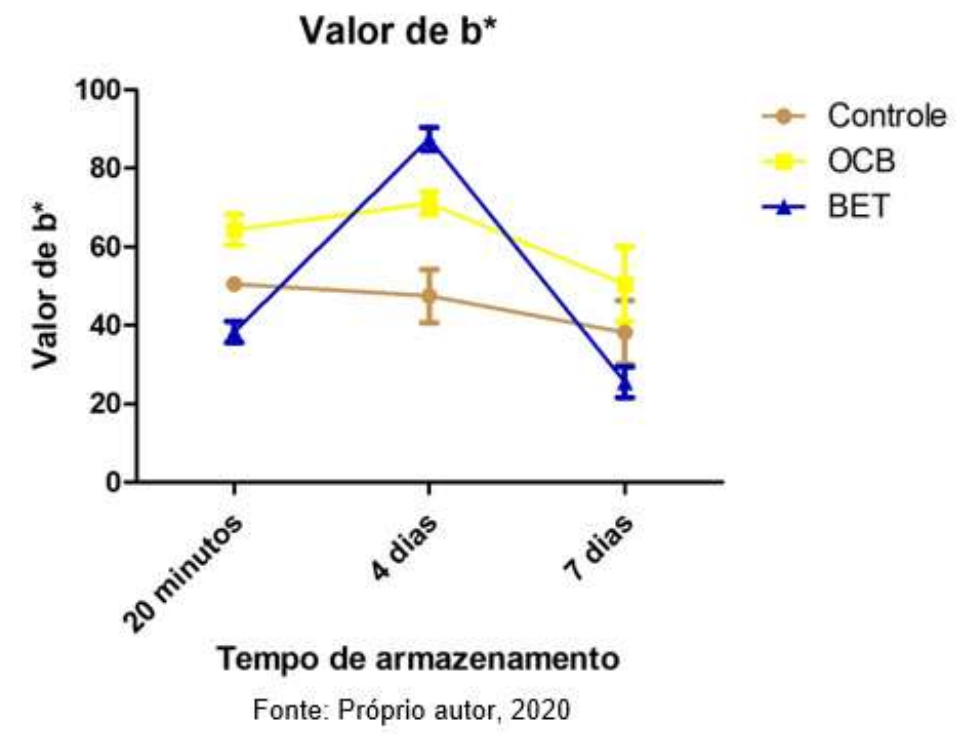

Para os valores de L* (Figura 3), que representam a luminosidade e leveza da carne, a amostra controle apresentou perda sucessiva no seu brilho e na luminosidade (aos 20 minutos $33,28 \pm 2,28$, ao $4^{\circ}$ dia, $25,61 \pm 3,65$ e ao $7^{\circ}$ dia, $23,45 \pm$ $0,88)$.

Figura 3 - Valor de $\mathrm{L}^{*}$ durante o armazenamento 20 minutos, 4 e 7 dias de armazenamento, de amostras de carne controle e tratadas com $10 \mu \mathrm{L} / \mathrm{g}$ de óleo copaíba bálsamo (Copaifera officinalis).

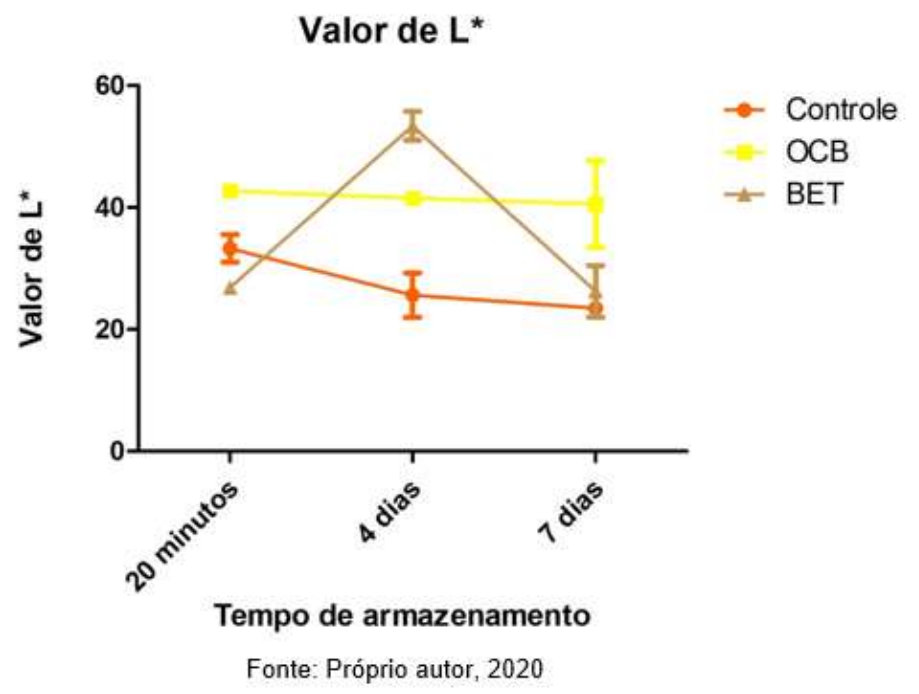


A amostra OCB apresentou uma maior estabilidade em seus valores, iniciando com 42,7 $\pm 0,8$ aos primeiros 20 minutos, ao $4^{\circ}$ dia, $41,55 \pm 0,91$ e ao $7^{\circ}$ dia, $40,58 \pm 7,11$. No entanto, a amostra BET, por sua vez, apresentou uma oscilação em seus valores de $L^{*}\left(26,85 \pm 0,05\right.$ aos 20 minutos, $53,36 \pm 2,36$ ao $4^{\circ}$ dia e $26,25 \pm 4,21$ ao $7^{\circ}$ dia) durante seu armazenamento. De acordo com Cardoso (2011), estas variações podem ocorrer em filmes biodegradáveis por se tornam menos translúcidos e mais suscetíveis a perda do brilho. No entanto, Tekce, et al. (2020) descreve que os antioxidantes presentes no próprio óleo quando em contato com a água podem alterar o brilho da carne. O tempo de armazenamento também tem sido relatado como fator capaz de interferir negativamente os valores L* (Al-Hijazeen, et al., 2016; Kim, et al., 2020). Desse modo, estes fatores podem ter atuado concomitantemente na alteração dos valores de L* (Figura 3) encontrados no presente trabalho.

\section{Análises microbiológicas}

Ao realizar as análises microbiológicas nos tempos de 20 minutos, 4 e 7 dias, verificou-se que nenhum dos tratamentos se mostraram melhores em relação a amostra controle ( $p>0,05)$, ou seja, a dosagem utilizada não foi suficiente para criar uma diferença significativa em relação a amostra controle, como indicado nas Figuras 4, 5 e 6.

Desse modo, entre as amostras de mesófilos aeróbios para as amostras controle verificou-se um aumento na população desses microrganismos de 3,06 a 5,27 log UFC/g à temperatura de $4 \pm 1^{\circ} \mathrm{C}$ no período de armazenamento, correspondente aos 20 minutos e se estendendo até o $7^{\circ}$ dia. Na amostra OCB, também foi possível observar aumento, partindo de 3,26 a 5,14 log UFC/g. E na amostra BET, partindo de 3,39 a 4,73 log UFC/g para o período e condições de armazenamento já citadas. Vale destacar, que os valores permaneceram limítrofes para as aeróbias mesófilas (até $10^{5} \mathrm{UFC} / \mathrm{g}$ ) conforme preconizado pela Instrução Normativa nº 60, de 23 de dezembro de 2019, da Agência Nacional de Vigilância Sanitária (ANVISA).

Figura 4 - Aeróbias mesófilas durante o armazenamento 20 minutos, 4 e 7 dias, de amostras de carne controle e tratadas com $10 \mu \mathrm{L} / \mathrm{g}$ de óleo copaíba bálsamo (Copaifera officinalis).

\section{Aeróbias mesófilas}

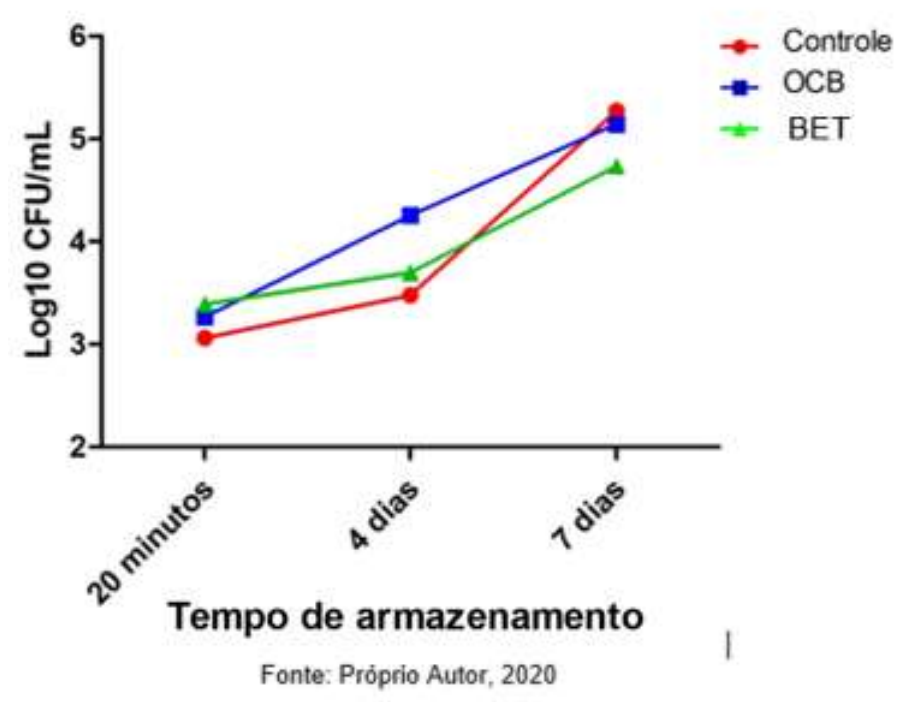

Na Figura 4, pode-se perceber que desde o período inicial de 20 minutos, não houve diferença significativa entre as amostras ( $p>0,05)$ perdurando até o final do armazenamento ( 7 dias). Estes achados também foram relatados por Quesada, et al., (2016) aplicando o óleo essencial de tomilho (Thymus vulgaris L.) em filme para aumento da vida de prateleira de carne bovina, constatando um aumento no número de aeróbias mesófilas, sendo este resultado atribuído à ausência do contato da 
carne com o revestimento, e consequentemente com o óleo. Já, no estudo realizado por Thanissery e Smith, (2014) aplicando a combinação do óleo de tomilho com o de laranja em frango, foi observada a redução dos mesófilos, sendo atribuída a ausência de pele do frango, que foi mais suscetível a ação da combinação dos óleos. No presente estudo, supõe-se que a dosagem tenha sido baixa para a composição da carne ou mesmo não tenha ocorrido a ruptura adequada da capsula formada pela rede de amido e óleo sob estudo.Em relação aos coliformes totais, a ANVISA não preconiza dados sobre a sua presença em alimentos, apenas na água. No entanto, foi avaliado a presença de $10^{6} \mathrm{UFC} / \mathrm{ml}$ de coliformes totais (Figura 5).

Figura 5 - Coliformes totais durante o armazenamento 20 minutos, 4 e 7 dias, de amostras de carne controle e tratadas com 10 $\mu \mathrm{L} / \mathrm{g}$ de óleo copaíba bálsamo (Copaifera officinalis).

\section{Coliformes totais}

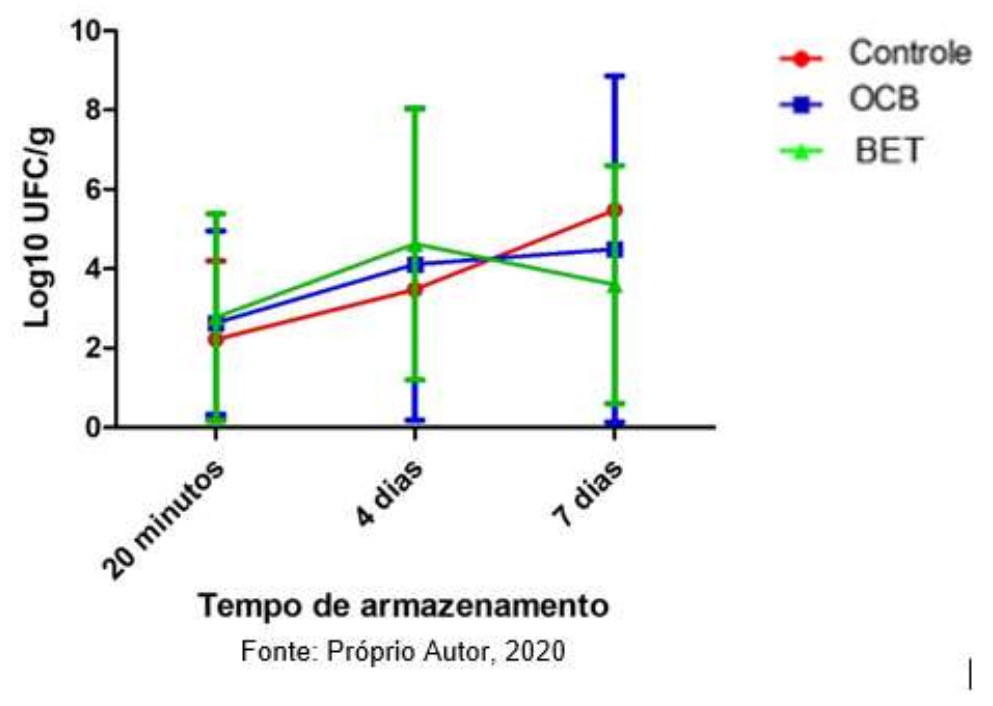

Na Figura 5, nota-se um crescimento de coliformes totais equivalente entre as três amostras: controle, OCB e BET, não havendo diferença significativa ( $p>0,05)$ entre elas.

No estudo de Adaszynska-Skwirzynska E Szczerbinska (2018), o óleo essencial de lavanda (Lavandula angustifolia) foi utilizado na água potável, e verificou-se que as bactérias intestinais (coliformes totais e Escherichia coli) tiveram redução, sendo atrelado aos seus compostos fenólicos e antioxidantes. Por outro lado, Silveira (2012) afirma que os coliformes totais foram reduzidos de maneira significativa $(\mathrm{p}<0,05)$ em amostras de linguiças, utilizando o óleo essencial de louro (Laurus nobilis L.).

Desse modo, os resultados encontrados no presente estudo podem estar relacionados a baixa dosagem, uma vez que segundo Burt (2004), para obter resultados favoráveis podem ser necessárias mais que duas vezes a dosagem bactericida encontrada in vitro para aplicação efetiva nos alimentos.

Apesar ter sido analisados, não foi encontrada a presença de Escherichia coli em nenhuma das amostras, o que pode ser explicado pela origem e qualidade da carne assim como a manipulação adequada da carne. E assim, para este parâmetro também conseguiu-se seguir o determinado pela Instrução Normatiza nº0/2019, ANVISA.

Ao analisar a presença de $P$. aeruginosa nota-se que também não houve diferença significativa entre as três amostras (p>0,05) (figura 6). 
Figura 6. Contagem de Pseudomonas aeruginosa durante o armazenamento 20 minutos, 4 e 7 dias, de amostras de carne controle e tratadas com $10 \mu \mathrm{L} / \mathrm{g}$ de óleo copaíba bálsamo (Copaifera officinalis).

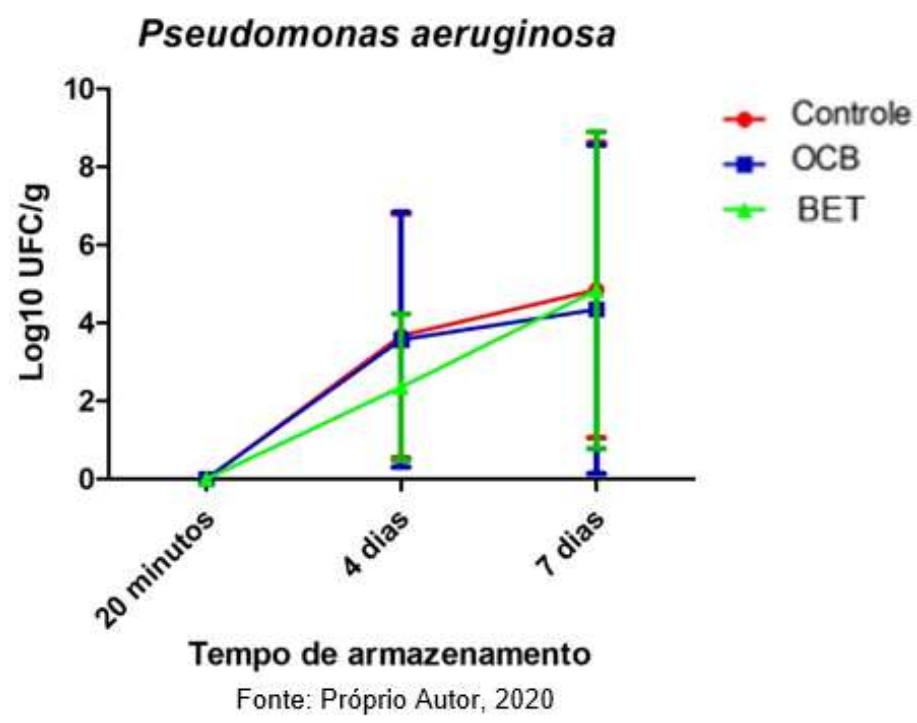

Na Figura 6, é possível observar que no tempo 20 minutos em nenhuma das amostras foi detectada a presença de $P$. aeruginosa, sendo constatadas apenas a partir dos 4 dias de armazenamento sob refrigeração, e contagens crescentes em todas amostras até o tempo 7 dias. A detecção tardia pode ser atribuída aos próprios requisitos de crescimento da Pseudomonas aeruginosa, cujo melhor desenvolvimento se dá nas temperaturas de 0 a $30^{\circ} \mathrm{C}$ e pH 6,0 (Alcantara, et al., 2012; Soares, et al., 2017; Thanissery \& Smith, 2014). Este fato observado também reforça a necessidade do respeito aos prazos de validade e demonstraram a veracidade do binômio tempo e temperatura na conservação dos alimentos.

De acordo com a Portaria CVS 5, de 09 de abril de 2013, os produtos cárneos quando mantidos até $4^{\circ} \mathrm{C}$ possuem validade de 3 dias, esses valores de temperaturas e dias de armazenamento, também são confirmados pela Instrução Normativa DIVISA/SVS N 4 de 04 de dezembro de 2014. Ou seja, os resultados encontrados ratificam a necessidade de seguimento a estes requisitos, tendo em vista aumento considerável em todos os microrganismos analisados a partir de 4 dias de armazenamento. No entanto, é importante ressaltar que nesse estudo apesar dos números terem sido crescentes, ainda assim no final dos 7 dias de armazenamento as contagens estavam dentro dos padrões brasileiros estabelecidos.

\section{Conclusão}

A utilização do óleo de copaíba bálsamo Copaifera officinalis) e o extrato de beterraba (Beta vulgaris L.) no gel da fécula de mandioca (Manihot esculenta) apresentou resultado favorável para a manutenção da qualidade organoléptica da carne, contribuindo para a segurança alimentar e nutricional dos consumidores. Desse modo, os resultados podem servir como base para novos estudos em busca de alternativas para conservação natural de matrizes alimentares e no controle de microrganismos patógenos e deteriorantes em alimentos.

\section{Referências}

ABIEC. (2019). Beef Report. Perfil da Pecuária no Brasil. Recuperado de: 〈http://www.abiec.com.br/controle/uploads/arquivos/sumario2019portugues.pdf〉.

Alarcon-Rojo, A. D., Carrillo-Lopez, L. M., Reyes-Villagrana, R., Huerta-Jiménez, M., \& Garcia-Galicia, I. A. (2019). Ultrasound and meat quality: A review. Ultrasonics Sonochemistry, 55, 369-382. 
Alcantara, M., Morais, I. C. L., Matos, C., \& Souza, O. C. C.(2012). Principais microrganismos envolvidos na deterioração das características sensoriais de derivados cárneos, Revista Brasileira de Higiene e Sanidade Animal, 6, 1, 1 a 20.

Al-Hijazeen, M., Lee, E., Mendonca, A., \& Ahn, D. (2016). Effect of Oregano Essential Oil (Origanum vulgare subsp. hirtum) on the Storage Stability and Quality Parameters of Ground Chicken Breast Meat. Antioxidants, 5(2), 18. 10.3390/antiox5020018.

ANVISA. (2018). Guia para determinação de prazos de validade de alimentos. <http://portal.anvisa.gov.br/documents/10181/5056443/Gu ia+16_2018+Prazo+de.pdf/e40032da-ea48-42ff-ba8c-a9f6fc7af7af>

ANVISA. (2019). Instrução normativa de $n^{o}$ 60, de 23 de dezembro de 2019. Estabelece as listas de padrões microbiológicos para alimentos. <https://www.in.gov.br/en/web/dou/-/instrucao-normativa-n-60-de-23-de-dezembro-de-2019-235332356>.

AOAC, 1995. Official methods of analysis. Gaithersburg, MD: Association of Official Analytical Chemists. Association of Official Analytical Chemists, Washington, DC Australian Tea Tree Industry Association (ATTIA). Australian Tea Tree oil (Melaleuca alternifolia). Recuperado de: https://teatree.org.au/teatree_about_harvesting.php.

Arruda, C., Aldana Mejía, J. A., Ribeiro, V. P., Gambeta Borges, C. H., Martins, C. H. G., Sola Veneziani, R. C., \& Bastos, J. K. (2019). Occurrence, chemical composition, biological activities and analytical methods on Copaifera genus-A review. Biomedicine \& Pharmacotherapy, 109, 1-20.

Boskovic, M., Zdravkovic, N., Ivanovic, J., Janjic, J., Djordjevic, J., Starcevic, M., \& Baltic, M. Z. (2015). Antimicrobial Activity of Thyme (Tymus vulgaris) and Oregano (Origanum vulgare) Essential Oils against Some Food-borne Microorganisms. Procedia Food Science, 5, 18-21.

Brasil. (2005). Consumo Sustentável: Manual de educação. Brasília - DF: Consumers International/ MMA/ MEC/ IDEC, (2a ed.).

Brasil. (2013). Ministério da Agricultura, Pecuária e Abastecimento. Projeções do Agronegócio: Brasil 2012/2013 a 2022/2023. Assessoria de Gestão Estratégica. (4a ed.), p. 46, Brasília - DF, 2013.

Brasil.(1993). Resolução de RDC 175, Portaria n. 1428 de 26 de novembro de 1993. Aprova o Regulamento técnico para Inspeção Sanitária de Alimentos. Órgão emissor: MS - Ministério de Saúde. <http://portal.anvisa.gov.br/documents/33916/388704/Portaria_MS_n_1428_de_26 _de_novembro_de_1993.pdf/6ae6ce0f-82fe-4e28-b0e1-bf32c9a239e0>

Brasil. (2019). Surtos de Doenças Transmitidas por Alimentos no Brasil: Informe 2018, 2019. <https://portalarquivos2.saude.gov.br/images/pdf/2019/fevereiro/15/Apresenta--o-Surtos-DTA---Fevereiro-2019.pdf>

Brasil. (2014). Instrução Normativa DIVISA/SVS N 4 DE 15/12/2014. Aprova o regulamento técnico sobre boas práticas para estabelecimentos comerciais de alimentos e para serviços de alimentação, e o roteiro de inspeção, anexo. 〈https://www.legisweb.com.br/legislacao/?id=281122>

Burt, S. (2004). Essential oils: their antibacterial properties and potential applications in foods-a review. International Journal of Food Microbiology, 94(3), $223-253$.

Cardoso, G. P. (2011). Revestimentos comestíveis à base de gelatina, glicerina, quitosana e óleos essenciais para conservação de carne bovina refrigerada. Universidade Federal de Lavras, Lavras.

Carvalho, R. J., de Souza, G. T., Honório, V. G., de Sousa, J. P., da Conceição, M. L., Maganani, M., \& Souza, E. L. (2015). Comparative inhibitory effects of Thymus vulgaris L. essential oil against Staphylococcus aureus, Listeria monocytogenes and mesophilic starter co-culture in cheese-mimicking models. Food Microbiology, 52, 59-65.

Carvalho, S. R. S. T, Manço, M. C. W. (2019). Cor: Métodos de Avaliação da Qualidade de Carnes. <https://www.fca.unesp.br/Home/Instituicao/Departamentos/Gestaoetecnologia/Teses/roca306.pdf>.

Carvalho, B.T., \& Zen, S. (2017). A cadeia de Pecuária de Corte no Brasil: evolução e tendências. Revista IPecege, 3(1), 85-99.

Dias, D. O., Colombo, M., Kelmann, R. G., De Souza, T. P., Bassani, V. L., Teixeira, H. F., ... Koester, L. S. (2012). Optimization of headspace solid-phase microextraction for analysis of $\beta$-caryophyllene in a nanoemulsion dosage form prepared with copaiba (Copaifera multijuga Hayne) oil. Analytica Chimica Acta, 721, 79-84.

Ferro, M., Masso, S., Souza, R., Moreno, M., \& Moreira, E. (2018). Meta-analysis on Copaiba Oil: Its Functions in Metabolism and Its Properties as an Antiinflammatory Agent. Journal of Morphological Sciences, 35(03), 161-166.

Franco, B. D. G. M., \& Landgraf, M. (2008). Microbiologia dos alimentos. Editora Atheneu, pág. 93 a 98, 2008.

Francomano, F., Caruso, A., Barbarossa, A., Fazio, A., La Torre, C., Ceramella, J., Sinicropi, M. S. (2019). $\beta$-Caryophyllene: A Sesquiterpene with Countless Biological Properties. Applied Sciences, 9(24), 5420.

Gomes, R. (2015). A produção científica em segurança alimentar e nutricional nos periódicos latino-americanos da base de dados SciELO. : https://dspace.unila.edu.br/bitstream/handle/123456789/571/A\%20PRODU\%C3\%87\%C3\%83O\%20CIENT\%C3\%8DFICA\%20EM\%20SEGURAN\%C3\%87 A\%20ALIMENTAR\%20E\%20NUTRICIONAL\%20NOS\%20PER\%C3\%8DODICOS\%20LATINO-AMERICANOS\%20DA\%20BASE\%20 DE\%20DADOS\%20SciELO.pdf?sequence=1\&isAllowed=y.

Gonçalves, L. C. P. et al. (2015). Betalaínas: das Cores das Beterrabas à Fluorescência das Flores. Revista Virtual de Química, 7, 1, 292-309.

Guimarães-Santos, A., Santos, D. S., Santos, I. R., Lima, R. R., Pereira, A., de Moura, L. S., Gomes-Leal, W. (2012). Copaiba Oil-Resin Treatment Is Neuroprotective and Reduces Neutrophil Recruitment and Microglia Activation after Motor Cortex Excitotoxic Injury. Evidence-Based Complementary and Alternative Medicine, 2012, 1-9. 10.1155/2012/918174

Kim, H.-J., Kim, H.-J., Jeon, J., Nam, K.-C., Shim, K.-S., Jung, J.-H., Jang, A. (2020). Comparison of the quality characteristics of chicken breast meat from conventional and animal welfare farms under refrigerated storage. Poultry Science, 99(3), 1788-1796. 
Limoni, B. H. S. et al. (2017). Influência do pH na qualidade da carne. Fundação Universidade Federal do Mato Grosso do Sul, Campo Grande, MS, 2017.

Martins, C. A. (2017). Efeito do pH final sobre a qualidade da carne de bovinos da raça Nelore. <https://www.repository.utl.pt/bitstream/10400.5/14814/1/Tese\%20C\%c3\%a1tia\%20Final\%20Corrigida.pdf> Acesso em 27 de nov. de 2019.

Montes, S. S, Neta, L. G. S, \& Cruz, R. S. (2013). Óleos essenciais em embalagens para alimentos - Revisão de literatura de 2000 a 2012 , Perspectivas da Ciência e Tecnologia, $5,1 / 2$.

Moraes, C. C, \& Junior, J. A. G. O. (2016). O consumidor brasileiro como barreira para implementação de inovações tecnológicas em embalagens de carne bovina in natura. Exacta, 14, 3, 353-366

Nollêto, A. P. R. (2018). Internet of things em logística: uma análise do uso de embalagem inteligente para distribuição de alimentos refrigerados. file:///C:/Users/Infowork/Downloads/Noletto_AnaPaulaReis_D.pdf.

Palma, S. F. (2017). Transformação do músculo em carne, influência na qualidade da carne. Beja, <https://repositorio.ipbeja.pt/bitstream/20.500.12207/4548/1/Ferro\%20Palma\%2C\%20S.\%20\%282017\%29\%20Li\%C3\%A7\%C3\%A3o.pdf>.

Pereira, A. V., Romanelli, P. F., Scriboni, A. B., \& Barboza, S. R. (2006). Estudo de estabilidade sob armazenamento da carne de ema (Rhea americana). Ciência e Tecnologia de Alimentos, 26(2), 283-289.

Ponce, A. G., Fritz, R., Del Valle, C., \& Roura, S. I. (2003). Antimicrobial activity of essential oils on the native microflora of organic Swiss chard. LWT Food Science and Technology, 36(7), 679-684.

Pombo, J. C. P., Ribeiro, E. R., Pinto, R. de L., \& Silva, B. J. M. (2018). Efeito antimicrobiano e sinergístico de óleos essenciais sobre bactérias contaminantes de alimentos. Segurança Alimentar e Nutricional, 25(2), 108-117.

Quesada, J., Sendra, E., Navarro, C., \& Sayas-Barberá, E. (2016). Antimicrobial Active Packaging including Chitosan Films with Thymus vulgaris L. Essential Oil for Ready-to-Eat Meat. Foods, 5(4), 57.

Rasooli, I., Rezaei, M. B., \& Allameh, A. (2006). Ultrastructural studies on antimicrobial efficacy of thyme essential oils on Listeria monocytogenes. International Journal of Infectious Diseases, 10(3), 236-241.

Rimini, S., Petracci, M., \& Smith, D. P. (2014). The use of thyme and orange essential oils blend to improve quality traits of marinated chicken meat. Poultry Science, 93(8), 2096-2102.

Salueña, H. B., Sáenz Gamasa, C., Diñeiro Rubial, J. M., \& Alberdi Odriozola, C. (2019). CIELAB color paths during meat shelf life. Meat Science, 157, 107889.

São Paulo. Portaria CVS 5, de 09 de abril de 2013. DOE de 19/04/2013 - nº 73 - Poder Executivo - Seção I - pág. 32 - 35 Aprova o regulamento técnico sobre boas práticas para estabelecimentos comerciais de alimentos e para serviços de alimentação, e o roteiro de inspeção, anexo. Secretária de Estado da Saúde.

Sarker, U., Islam, M. T., Rabbani, M. G., \& Oba, S. (2018). Variability in total antioxidant capacity, antioxidant leaf pigments and foliage yield of vegetable amaranth. Journal of Integrative Agriculture, 17(5), 1145-1153. 10.1016/s2095-3119(17)61778-7

Shourav, A. H., Hasan, M., \& Ahmed, S. (2020). Antibiotic susceptibility pattern of Listeria spp. isolated from cattle farm environment in Bangladesh. Journal of Agriculture and Food Research, 2, 100082. 10.1016/j.jafr.2020.100082

Silva, C. S., Figueiredo, H. M., Stamford, T. L. M. \& Silva, L. H. M. (2019). Inhibition of Listeria monocytogenes by Melaleuca alternifolia (tea tree) essential oil in ground beef. International Journal of Food Microbiology, 293, 79-86. 10.1016/j.ijfoodmicro.2019.01.004

Silva, M. R. L. (2019). Aplicação de revestimento à base de quitosana incorporado com o extrato do resíduo de cebola (Allium cepa l.) em carne bovina. <https://repositorio.ufersa.edu.br/bitstream/prefix/4479/1/MariaRLS_DISSERT.pdf>

Silveira, S. M. (2012). Avaliação da atividade antimicrobiana e antioxidante de extratos vegetais e óleos essenciais e aplicação do óleo essencial de louro (L. nobilis) como agente conservador natural em embutido cárneo frescal. https://repositorio.ufsc.br/handle/123456789/100520.

Smith, R. L., Cohen, S. M., Doull, J., Feron, V. J., Goodman, J. I., Marnett, L. J., Adams, T. B. (2005). A procedure for the safety evaluation of natural flavor complexes used as ingredients in food: essential oils. Food and Chemical Toxicology, 43(3), 345-363.

Soares, K. M. P, Silva J. B. A., Góis, V. A. (2017). Parâmetros de qualidade de carnes e produtos cárneos: uma revisão. Higiene e Microbiologia. 31(268/269): 87-94

Sousa, R. D. M. (2018). Estudos de substâncias químicas em óleos de coco, copaíba, calêndula e girassol utilizados no tratamento de feridas: Uma abordagem teórica. <https://monografias.ufma.br/jspui/bitstream/123456789/2357/1/RafaelSousa.pdf>

Souza, L. A., Pozza, P. C., Madrona, G. S., Pintro, P. T. M., Knupp, I. S., Silva Júnior, R. C., Pozza, M. S. S. (2020). Atividade antimicrobiana de óleo de alecrim (Rosmarinus officinalis L.) em carnes inoculadas com Escherichia coli. Brazilian Applied Science Review, 4(2), 592-605.

Tekce, E. (2020). Effects of an Essential Oil Mixture Added to Drinking Water for Temperature-Stressed Broilers: Performance, Meat Quality, and Thiobarbituric Acid-Reactive Substances. Journal of Applied Poultry Research, 29 (1), 77-84.

Thanissery, R, \& Smith, D. P. (2014). Effect of marinade containing thyme and orange oils on broiler breast fillet and whole wing aerobic bacteria during refrigerated storage. Journal of Applied Poultry Research, 23 (2), p. 228-232.

Zhang, Y., Hopkins, D. L., Zhao, X., Van De Ven, R., Mao, Y., Zhu, L., Luo, X. (2018). Characterisation of pH decline and meat color development of beef carcasses during the early postmortem period in a Chinese beef cattle abattoir. Journal of Integrative Agriculture, 17(7), 1691-1695. 